\title{
Effects of Temperature on Urediniospore Germination, Germ Tube Growth, and Initiation of Infection in Soybean by Phakopsora Isolates
}

\author{
M. R. Bonde, D. K. Berner, S. E. Nester, and R. D. Frederick
}

U.S. Department of Agriculture-Agricultural Research Service, 1301 Ditto Ave., Fort Detrick, MD 21702.

Accepted for publication 17 March 2007.

\begin{abstract}
Bonde, M. R., Berner, D. K., Nester, S. E., and Frederick, R. D. 2007. Effects of temperature on urediniospore germination, germ tube growth, and initiation of infection in soybean by Phakopsora isolates. Phytopathology 97:997-1003.

Temperature is a critical factor in plant disease development. As part of a research program to determine how specific environmental variables affect soybean rust, we determined temperature effects on urediniospore germination and germ tube growth of four isolates of Phakopsora pachyrhizi, one each from Brazil, Hawaii, Taiwan, and Zimbabwe, and an

period on initiation of disease by the $P$. pachyrhizi isolates. All variables were fit to a nonlinear beta function with temperature as the independent variable. Minimum, maximum, and optimum temperatures, along with shape parameters of the beta function for each variable, were statistically analyzed. All Phakopsora isolates behaved similarly as to how temperature affected urediniospore germination, germ tube growth, and initiation of disease. The results suggest that $P$. pachyrhizi has changed little in the past few decades with respect to how it responds to temperature and that previously collected research data continues to be valid, simplifying the development of soybean rust disease models.
\end{abstract} isolate of $P$. meibomiae from Puerto Rico, collected over a 25-year period. Also compared were the effects of temperature during a night dew
Additional keywords: thermogradient plate.
Soybean rust, incited by Phakopsora pachyrhizi Syd., has been known in Asia since 1902 (9), and adversely affects soybean production in Asia and Australia (4). In 1994, the pathogen was discovered in fields in Hawaii (11). In 1996, the disease was detected for the first time in central Africa, and by 2001 had spread to South Africa (12). Also in 2001, soybean rust was discovered in Paraguay, the first report in the New World (18), and shortly thereafter in Brazil (24).

In November 2004, the Louisiana Department of Agriculture and the U.S. Department of Agriculture (USDA) jointly reported the first documented case of soybean rust in the United States, which was verified by polymerase chain reaction (PCR) (20). Since that time, state departments of agriculture, universities, industry groups, and the USDA have cooperated in an effort to lessen any possible impact of the disease to the U.S. soybean industry.

$P$. meibomiae, although known for many decades to infect legume species other than soybean (19), was first detected on soybean in 1976 in the Limani Valley, Puerto Rico (23). At that time, it was erroneously believed to be P. pachyrhizi (4). Taxonomic clarification of the rust causing agents came in 1992 when Ono et al. (19) reported that two rust pathogens caused rust on soybean. $P$. pachyrhizi, the more aggressive of the two pathogens, could greatly reduce soybean yields, whereas $P$. meibomiae caused little economic loss to soybean (17).

Beginning in 1972, Melching et al. (15) conducted research in the Biological Safety Level 3 (BSL3-P) plant disease containment facility at USDA-ARS, Frederick, MD. Their results have con-

Corresponding author: M. R. Bonde; E-mail address: morris.bonde@ars.usda.gov

doi:10.1094/PHYTO-97-8-0997

This article is in the public domain and not copyrightable. It may be freely reprinted with customary crediting of the source. The American Phytopathological Society, 2007. tributed to a better understanding of the biology and environmental requirements of soybean rust $(3-5,10,13,14,16)$ and include information on effects of temperature and moisture on urediniospore germination and infection of soybean $(13,14,16)$. The isolates they used were preserved in liquid nitrogen refrigerators and remain available for research today. We used their isolates, in addition to others collected more recently from Hawaii, Africa, and South America, to compare the effects of temperature on urediniospore germination, germ tube growth, and initiation of disease during a dew period. The objective of our research was to define the effects of temperature on initial establishment of soybean rust and determine if isolates from different geographical locations and periods of time respond similarly to temperature. This is part of a broader research program to provide information that can be used to develop soybean rust prediction models. We anticipate eventually reporting results from other epidemiological studies involving other portions of the disease cycle, and include results using isolates collected within the United States. We have included P. meibomiae because of the pathogen's proximity to continental United States and the possibility that it could be confused in the field with P. pachyrhizi.

\section{MATERIALS AND METHODS}

Isolates. Four isolates of $P$. pachyrhizi and one of $P$. meibomiae were used in the study. The isolates of $P$. pachyrhizi were Brazil 01-1 (=BZ01-1), Hawaii 94-1 (HW94-1), Taiwan 80-2 (TW80-2), and Zimbabwe 01-1 (ZM01-1). P. meibomiae isolate Puerto Rico 76 (PR76) (4) was included for comparison. The location and year that each respective isolate was obtained from the field is indicated by the isolate designation. For example, BZ01-1 is an isolate collected in Brazil in 2001 and HW94-1 was collected in Hawaii in 1994. Isolates HW94-1 and PR76 were used only in studies to determine effects of temperature on germination and germ tube growth and were not used in studies to determine 
effects of temperature on disease development. All isolates used in this study are preserved in the culture collection at the USDAARS, Foreign Disease-Weed Science Research Unit, Fort Detrick, MD, under the appropriate APHIS permit.

Collection and maintenance of urediniospores. Each isolate was originally received as numerous urediniospores on infected leaves collected in the field or as urediniospores collected from the field on cotton swabs. After being sent to the ARS containment laboratory, these were increased and maintained in greenhouses on soybean cv. Wayne or Williams. Urediniospores for research or storage were collected from infected plants by means of a spore collector vacuum device (6) beginning 10 to 14 days after inoculation and continuing at weekly intervals. Subsamples periodically were placed in storage in liquid nitrogen $\left(-196^{\circ} \mathrm{C}\right)$ refrigerators for use in later experiments or long-term preservation.

Prior to plant inoculations, urediniospores from liquid nitrogen storage were heat-shocked dry for $5 \mathrm{~min}$ in sealed ampoules submerged in a $40^{\circ} \mathrm{C}$ water bath. Following the heat treatment, urediniospores were removed from the ampoules and hydrated in an atmosphere at approximately $100 \%$ relative humidity $(\mathrm{RH})$ by placement in plastic weighing boats floating on water in closed petri dishes.

Temperature-gradient plate. The temperature-gradient plate used in our experiments was a major modification of a gradient plate constructed and used earlier by Halldal and French (8). Ours is the same as that used by Marchetti et al. (13) in the early 1970s, however never fully described. We modified their plate by the addition of styrofoam insulation that separated the plate into 11 temperature compartments.

The modified plate was a $41-$ by $179-\mathrm{cm}$ piece of aluminum (1.3-cm-thick). At each end of the plate rested a stainless steel box (39 $\mathrm{cm}$ deep by $20 \mathrm{~cm}$ wide by $76 \mathrm{~cm}$ tall). One box contained ethylene glycol cooled by a submerged copper coil through which coolant was circulated from a refrigeration unit, and the box at the other end of the temperature-gradient plate contained distilled water heated by a submersion heater. As a result of the cold and hot boxes at opposite ends, a temperature gradient was imposed along the aluminum plate. The entire unit rested on a 5 -cm-thick piece of styrofoam for insulation. The sides of the plate and hot and cold baths were insulated with 1-in.-thick pieces of styrofoam, and $2.5-\mathrm{cm}$-thick pieces of styrofoam were placed over the baths to serve as lids.

On the 137-cm length of aluminum between the hot and cold baths rested a 1.9-cm-thick styrofoam grid divided into $11 \mathrm{com}-$ partments, each 7.6 by $30 \mathrm{~cm}$, the latter dimension spanning the width of the temperature-gradient plate. During experiments, each compartment held nine 35-mm-diameter plastic petri dishes seeded with urediniospores. The temperature in each compartment was monitored throughout each experiment by means of a thermocouple in contact with the agar surface in a 35 -mm-diameter temperature-monitoring dish placed $3.8 \mathrm{~cm}$ from the edge of the temperature-gradient plate. Each thermocouple was linked to a temperature recorder by means of a wire passing through the styrofoam insulation and through the side of the temperaturemonitoring dish by means of a hole bored through the plastic.

Determination of temperature variation within urediniospore-seeded petri dishes. The temperature variation at the agar surface within and among petri dishes within a compartment was determined in a series of experiments in which temperature was continuously monitored for several hours by means of calibrated thermocouples. Each thermocouple was individually calibrated from 0 to $39^{\circ} \mathrm{C}$ by comparison of the temperature readings with that of a mercury-bulb thermometer. Included in the reference temperature was $0^{\circ} \mathrm{C}$ of an ice-water mixture.

Effects of temperature on urediniospore germination and germ tube growth. Plastic petri dishes ( $35 \mathrm{~mm}$ in diameter), each containing $3.0 \mathrm{ml}$ of $1.25 \%$ water agar, were placed on the surface of the aluminum temperature-gradient plate, and agar tempera- tures were allowed to come to equilibrium with the temperatures at the surface of the gradient plate. Mean temperatures at the agar surface ranged from approximately $7^{\circ} \mathrm{C}$ at one end of the temperature-gradient plate to $32^{\circ} \mathrm{C}$ at the other end. In each experiment, 11 temperature compartments, separated by approximately $2.5^{\circ} \mathrm{C}$, were tested.

Urediniospores were seeded onto the surface of agar in dishes in the following manner. Petri dish lids were placed on the floor of a spore-settling tower (2) with their inside surfaces facing up. A cloud of urediniospores was released into the tower by means of a $\mathrm{CO}_{2}$ pistol, and urediniospores were allowed to settle onto the inside surfaces of the lids. A horizontal metal plate inserted into the spore-settling tower above the open agar dishes, and retracted $3 \mathrm{~s}$ after urediniospore release, prevented urediniospore clumps, which fell faster than single urediniospores, from being deposited on the lids. After at least an additional 10 min (the exact time not critical), lids containing nonclumped urediniospores were removed from the tower and one lid placed on each agar dish on the temperature-gradient plate. The lids were sharply tapped with a screwdriver handle to dislodge urediniospores and transfer urediniospores to the agar surface.

In order to accommodate nine dishes (three dishes per isolate) at each temperature, dishes were staggered, arranged arbitrarily within the temperature compartments. After a 3-h incubation period, the dishes were removed from the temperature-gradient plate, lids were removed, and plates were placed in a formaldehyde-saturated atmosphere (over formaldehyde) in a desiccator jar to halt further urediniospore germination and germ tube growth. The 3-h run was followed the next day by a 6-h run using the same isolates. The experiment (comprised of a 3- and 6-h run) was repeated two additional times. The three experiments, conducted from 1994 to 1995, were considered the first set of tests and included isolates $P$. pachyrhizi HW94-1 and TW80-2 and P. meibomiae PR76.

A second set of tests, also comprised of three experiments, was conducted from 2004 to 2005, and included isolates P. pachyrhizi BZ01-1, TW80-2, and ZM01-1. The first and second sets of tests used the same experimental design.

Germination percentages at 3- or 6-h incubation were determined by means of microscopic examination of 100 and 400 urediniospores in the first and second set of tests, respectively, at $\times 100$ magnification in each of the triplicate dishes per temperature per isolate. Individual urediniospores were considered germinated if the germ tube was equal to or greater than the minor diameter of the parent urediniospore. Average germ tube lengths at 3- or 6-h incubation were based on measurements, by means of an ocular micrometer, of 10 germ tubes per each of the three replicate dishes for each temperature and duration of incubation.

Analyses of data from the temperature-gradient plate. Data from the two sets of tests (three experiments each) were analyzed separately. This was required because the effects attributable to the fungus isolates, with the exception of the Taiwan isolate, were confounded between the two time periods when the study was conducted. Because absolute urediniospore germinability differed among rust isolates within the same experiment, and for the respective isolates between experiments, data for germination percentages were adjusted to compensate for differences not attributable to temperature. This was accomplished by adjusting the maximum germination percentage for each isolate to $100 \%$.

All statistical analyses were done using the Statistical Analysis System (SAS Institute, Cary, NC; version 9.1). The experimental design was nested with petri dishes nested within experiments nested within isolates with temperature as the independent variable in the statistical analyses.

All observations among petri dishes within experiments for each isolate at each temperature were independent. Nonlinear regression analyses were done by using the NLIN procedure of SAS for each isolate and time of observation (3 and $6 \mathrm{~h}$ ) to 
generate regression equations. The nonlinear model used to describe temperature response was a generalized beta function where $y=\mathrm{b} 1\left[\left(T-T_{\min }\right)^{\mathrm{b} 3}\left(T_{\max }-T\right)^{\mathrm{b} 5}\right]$. For this model, $y=$ percent maximum urediniospore germination or germ tube length; $T=$ temperature; $T_{\min }=$ minimum temperature for germination or germ tube growth; $T_{\max }=$ maximum temperature for germination or germ tube growth; and b1, b3, and b5 were parameters estimated from the nonlinear regressions $(1,7) . R^{2}$ values were calculated from the nonlinear regression analyses as $1-\left(\mathrm{SS}_{\text {error }} / \mathrm{SS}_{\mathrm{total}}\right)$.

Nonlinear regressions were conducted for each experiment within each year (1996 or 2005), time of observation (3 or 6 h), and isolate combination with values from each petri dish. From these analyses, the parameters $T_{\min } ; T_{\max }$; the observed optimum temperature for the responses $\left[T_{\text {opt }}(\right.$ observed $\left.)\right] ; \mathrm{b} 1 ; \mathrm{b} 3 ; \mathrm{b} 5$; the standard errors of b1, b3, and b5; and the optimum temperature for the response from the predicted $y$ values $\left[T_{\text {opt }}\right.$ (predicted)] were recorded for each experiment in a separate data set. These data were analyzed by analysis of variance (ANOVA) with the general linear models procedure of SAS to generate means of the parameters for each isolate in each year and time of observation and to determine any significant differences in means among isolates for each parameter. Analyses of the shape parameters b1, b3, and b5 were weighted with the inverse of the standard errors of each parameter for each isolate in each experiment.

To visualize temperature responses of percent maximum urediniospore germination and germ tube growth, separate nonlinear regression analyses were conducted on the combined data from all experiments by using means of the values from the petri dishes. Representative regression lines from these analyses were plotted, along with the respective means and standard errors, for the common isolate (TW80-2) tested in both years, using SigmaPlot for Windows version 10.0, Systat Software, Inc.

Effect of temperature during a dew period on disease development. Soybean plants of 'Williams' were grown in a greenhouse. At 1 month, 32 plants at the three- to four-trifoliolate growth stage were inoculated by spraying $5 \mathrm{ml}$ per plant of a urediniospore suspension of BZ01-1, TW80-2, or ZM01-1 at $2 \times$ $10^{4}$ or $3 \times 10^{4}$ urediniospores per $\mathrm{ml}$, depending on the experiment, per milliliter of sterile distilled water containing $0.01 \%$ Tween 20 (sodium monolaurate). Ten-centimeter-diameter plastic petri dishes containing water agar also were sprayed to determine germinability of the urediniospores used as inoculum. Inoculated plants and germination dishes were incubated over night at $20^{\circ} \mathrm{C}$.

Each of eight dew chambers was calibrated to operate at an average temperature, from 7 to $32^{\circ} \mathrm{C}$, and monitored by means of a data logger (Hobo Pro RH/Temp H08-032-08; Onset Computer Corp., Pocasset, MA). For each pathogen isolate, four plants were placed in each chamber. After $16 \mathrm{~h}$ in dew, the inoculated plants were removed from the dew chambers, allowed to dry in a hallway at room temperature (approximately $22^{\circ} \mathrm{C}$ ), and then placed randomly on a bench in the greenhouse for disease development.

Fourteen days after inoculation, the three leaflets for each of three trifoliolate leaves for each plant per isolate per temperature were excised from the plants and placed in trays in a refrigerator at $4{ }^{\circ} \mathrm{C}$. The next day, digital photographs were taken of each leaflet using back lighting from a light box. The photographs later were examined to determine the average number of lesions per square centimeter for each of the four replicate plants for each isolate at each temperature. The experiment was repeated three additional times.

Analysis of data from the dew temperature study. All statistical analyses were done using SAS. The experimental design was nested with the means of the three trifoliolate leaves (each a sample) within plants within each of the four runs of the experiment for each isolate as the experimental units. The dependent variables in these analyses were lesions per square centimeter and percent maximum lesion numbers. The percentage of maximum lesion numbers was used as a way to compensate for differences in lesion numbers within and among experiments having nothing to do with response to temperature. Percent maximum lesion numbers was calculated for each individual inoculated plant as a percentage of the highest number of lesions per square centimeter for that isolate (i.e., set at 100\%) within the experiment. Data for both variables were analyzed by nonlinear regression and ANOVA as described for urediniospore germination and germ tube growth.

\section{RESULTS}

Temperature variation at each specific location along the temperature-gradient plate was $\pm 0.2^{\circ} \mathrm{C}$ within an experiment, and the temperatures within compartments varied a maximum of $\pm 0.4^{\circ} \mathrm{C}$ from the average temperature.

In both sets of tests (1996 and 2005), there were no significant $(P \leq 0.05)$ differences among isolates for any of the temperature response parameters for percent maximum urediniospore germination at either time ( 3 or $6 \mathrm{~h}$ ) of observation (Tables 1 and 2). Overall mean predicted optimum temperatures differed from overall mean observed optimum temperatures by less than $1^{\circ} \mathrm{C}$ for each time of observation in each year (1996 or 2005) (Tables 1 and 2). Predicted optimum germination ranged from 21.80 to $24.30^{\circ} \mathrm{C}$ among all isolates within the two sets of tests and varied among isolates by a maximum of $1.62^{\circ} \mathrm{C}$ at $3 \mathrm{~h}$ in $1996,0.90^{\circ} \mathrm{C}$ at $6 \mathrm{~h}$ in $1996,0.26^{\circ} \mathrm{C}$ at $3 \mathrm{~h}$ in 2005 , and $2.36^{\circ} \mathrm{C}$ at $6 \mathrm{~h}$ in 2005 . A representative temperature response of percentage of maximum urediniospore germination is illustrated by isolate TW80-2 in

TABLE 1. Means of observed minimum, maximum, and optimum temperatures for percentage of maximum urediniospore germination and means of beta function ${ }^{y}$ parameters, $R^{2}$ values for data fit to model, and predicted optimum temperatures for two isolates of Phakopsora pachyrhizi and one isolate of P. meibomiae (PR76) after 3 or $6 \mathrm{~h}$ incubation in 1996

\begin{tabular}{|c|c|c|c|c|c|c|c|c|}
\hline Isolate & $T_{\min }$ & $T_{\max }$ & b1 & b3 & b5 & $\begin{array}{c}T_{\mathrm{opt}} \\
\text { (observed) } \\
\end{array}$ & $\begin{array}{c}T_{\mathrm{opt}} \\
\text { (predicted) }\end{array}$ & $R^{2}$ \\
\hline \multicolumn{9}{|l|}{$3 \mathrm{~h}$ incubation } \\
\hline HW94-1 & 12.60 & 29.26 & 9.73 & 0.45 & 0.24 & 25.03 & 24.20 & 0.98 \\
\hline TW80-2 & 12.60 & 28.26 & 1.01 & 0.83 & 0.43 & 24.16 & 23.27 & 0.89 \\
\hline Mean & 12.28 & 29.10 & 4.47 & 0.62 & 0.35 & 24.15 & 23.35 & \\
\hline Probability difference $\alpha=0.05$ & $\mathrm{NS}^{\mathrm{z}}$ & NS & NS & NS & NS & NS & NS & \\
\hline \multicolumn{9}{|l|}{$6 \mathrm{~h}$ incubation } \\
\hline TW80-2 & 9.27 & 30.43 & 1.51 & 0.93 & 0.48 & 23.40 & 24.30 & 0.97 \\
\hline Mean & 10.01 & 29.75 & 12.44 & 0.60 & 0.34 & 23.42 & 23.98 & \\
\hline Probability difference $\alpha=0.05$ & $\mathrm{NS}^{\mathrm{z}}$ & NS & NS & NS & NS & NS & NS & \\
\hline
\end{tabular}

${ }^{\mathrm{y}} y=\mathrm{b} 1\left[\left(T-T_{\min }\right)^{\mathrm{b} 3}\left(T_{\max }-T\right)^{\mathrm{b} 5}\right] ; y$, percentage of maximum urediniospore germination; $T$, temperature $\left({ }^{\circ} \mathrm{C}\right) ; \mathrm{b} 1, \mathrm{~b} 3$, b5, model parameters; $T_{\min }$, minimum temperature $\left({ }^{\circ} \mathrm{C}\right)$ for germination; $T_{\max }$, maximum temperature $\left({ }^{\circ} \mathrm{C}\right)$ for germination.

${ }^{\mathrm{z}} \mathrm{NS}=$ means among isolates not significantly different at $\leq 0.05$. 
1996 at $6 \mathrm{~h}$ in Figure 1. Percentage of maximum germination gradually rose to a maximum and then abruptly declined. The same general response was found for the other isolates in both years of the tests.

There were no significant $(P \leq 0.05)$ differences among isolates for any of the temperature response parameters for germ tube length in either test at either time of observation (Tables 3 and 4). Overall mean predicted optimum temperatures differed from overall mean observed optimum temperatures by less than $1^{\circ} \mathrm{C}$ for each time of observation in each year. Predicted optimum temperature for germ tube length ranged from 21.00 to $24.37^{\circ} \mathrm{C}$ and varied among isolates by a maximum of $1.25^{\circ} \mathrm{C}$ at $3 \mathrm{~h}$ in 1996 , $1.30^{\circ} \mathrm{C}$ at $6 \mathrm{~h}$ in $1996,1.47^{\circ} \mathrm{C}$ at $3 \mathrm{~h}$ in 2005 , and $0.00^{\circ} \mathrm{C}$ at $6 \mathrm{~h}$ in 2005. A representative temperature response of germ tube length for isolate TW80-2 in 2005 at $3 \mathrm{~h}$ is presented in Figure 1. Germ tube length gradually rose to a maximum and then abruptly declined. The same general temperature response was found for the other isolates in both years of the tests.

For disease development, following a nighttime dew period, the shape parameter b5 for number of lesions per square centimeter (Table 5) was significantly greater for BZ01-1 than for ZM01-1. No other significant differences among isolates were found for this variable. For maximum percent lesions (Table 5), the observed optimum temperature was significantly greater for BZ01-1 than for TW80-2. No other significant differences among isolates were found for this variable. Overall mean predicted optimum temperatures differed from overall mean observed optimum temperatures by less than $1^{\circ} \mathrm{C}$ for each variable. Predicted optimum temperature for lesions per square centimeter varied among isolates by a maximum of $0.73^{\circ} \mathrm{C}$, and the predicted optimum temperature for maximum percent lesions among isolates by a maximum of $3.43^{\circ} \mathrm{C}$. As evident from the $R^{2}$ values (Table 5), more variability was observed for these two variables than for percent maximum germination or germ tube length. However, the same general temperature response was found for these variables as for the other variables: a gradual rise to a maximum followed by an abrupt decline.

\section{DISCUSSION}

With the recent spread of soybean rust from Asia to Africa to South America, and finally to the United States, interest has sharply risen in soybean rust. Part of this interest has been in the relationship of specific environmental variables, particularly moisture and temperature, to development of soybean rust. Knowledge of $P$. pachyrhizi reactions to temperature and moisture is required in order to significantly improve rust prediction models. Most information available today was obtained 15 to 35 years ago in Australia or Asia, or in the USDA-ARS plant disease containment facility at Fort Detrick, MD, using isolates from Australia and Asia. Because pathogens can change over time, it is possible that this information is no longer applicable.
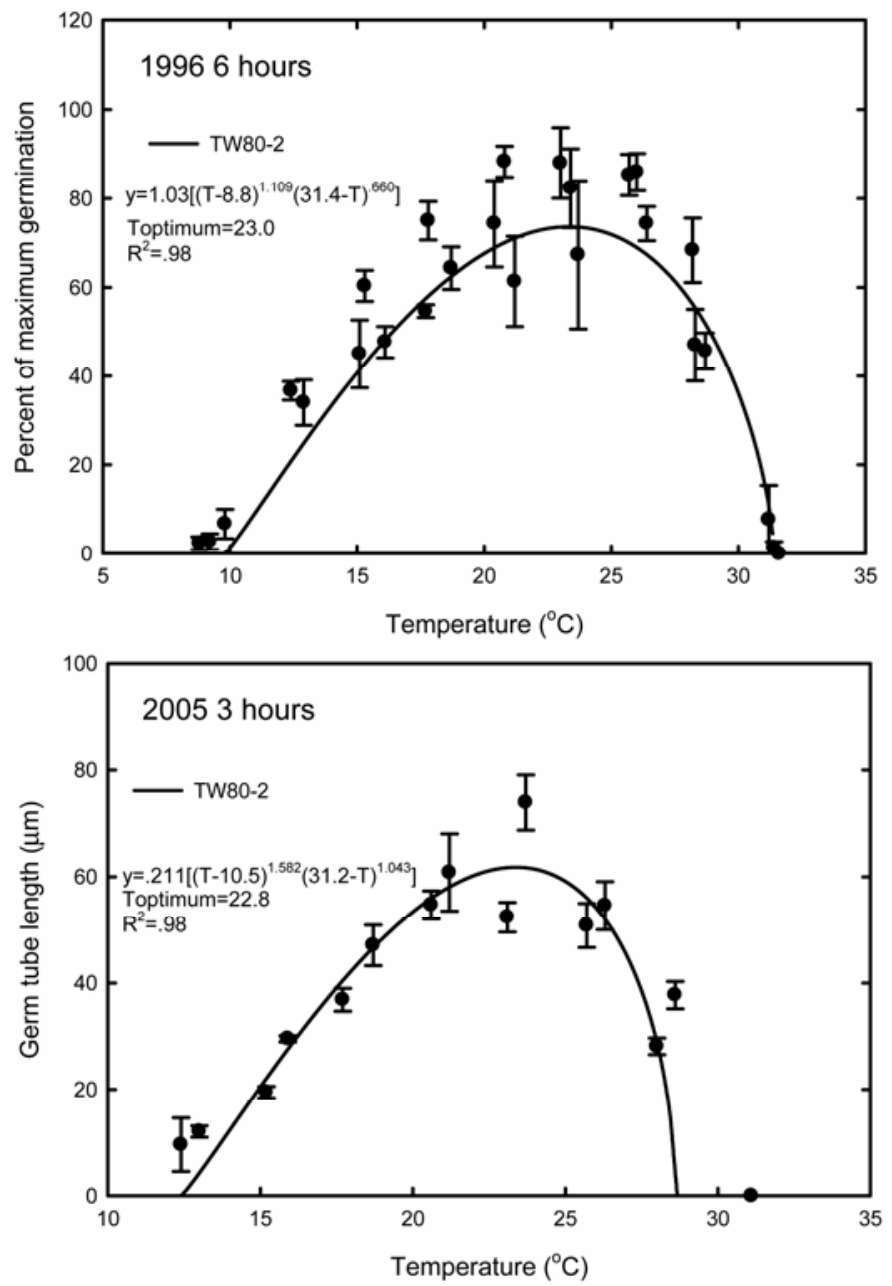

Fig. 1. Effect of temperature on percentage of maximum urediniospore germination after $6 \mathrm{~h}$ incubation in 1996 and germ tube length after $3 \mathrm{~h}$ incubation in 2005 for Phakopsora pachyrhizi isolate TW80-2. Data points are means of maximum percent germination or germ tube length from three petri dishes in three experiments along with associated standard errors (bars). The lines show the generalized beta function fitted to the combined data from three experiments with nonlinear regression and are representative of the responses of other P. pachyrhizi isolates tested.

TABLE 2. Means of observed minimum, maximum, and optimum temperatures for percentage of maximum urediniospore germination and means of beta function ${ }^{y}$ parameters, $R^{2}$ values for fit to model, and predicted optimum temperatures for three isolates of Phakopsora pachyrhizi after 3 or $6 \mathrm{~h}$ incubation in 2005

\begin{tabular}{|c|c|c|c|c|c|c|c|c|}
\hline Isolate & $T_{\min }$ & $T_{\max }$ & b1 & b3 & b5 & $\begin{array}{c}T_{\mathrm{opt}} \\
\text { (observed) } \\
\end{array}$ & $\begin{array}{c}T_{\mathrm{opt}} \\
\text { (predicted) }\end{array}$ & $R^{2}$ \\
\hline \multicolumn{9}{|l|}{$3 \mathrm{~h}$ incubation } \\
\hline BZ01-1 & 10.50 & 29.63 & 3.69 & 0.81 & 0.51 & 22.60 & 23.16 & 0.99 \\
\hline ZM01-1 & 10.50 & 29.90 & 3.62 & 0.75 & 0.39 & 23.96 & 22.90 & 0.98 \\
\hline Mean & 10.14 & 29.53 & 2.59 & 0.78 & 0.44 & 23.05 & 23.05 & \\
\hline Probability difference $\alpha=0.05$ & $\mathrm{NS}^{\mathrm{z}}$ & NS & NS & NS & NS & NS & NS & \\
\hline \multicolumn{9}{|l|}{$6 \mathrm{~h}$ incubation } \\
\hline ZM01-1 & 9.73 & 30.10 & 14.06 & 0.48 & 0.27 & 23.33 & 23.43 & 0.99 \\
\hline Mean & 9.36 & 29.67 & 10.40 & 0.49 & 0.27 & 22.64 & 23.13 & \\
\hline Probability difference $\alpha=0.05$ & NS & NS & NS & NS & NS & NS & NS & \\
\hline
\end{tabular}

${ }^{\mathrm{y}} y=\mathrm{b} 1\left[\left(T-T_{\min }\right)^{\mathrm{b} 3}\left(T_{\max }-T\right)^{\mathrm{b} 5}\right] ; y$, percentage of maximum urediniospore germination; $T$, temperature $\left({ }^{\circ} \mathrm{C}\right)$; b1, b3, and b5, model parameters; $T_{\min }$, minimum temperature $\left({ }^{\circ} \mathrm{C}\right)$ for germination; $T_{\max }$, maximum temperature $\left({ }^{\circ} \mathrm{C}\right)$ for germination.

${ }^{\mathrm{z}} \mathrm{NS}=$ means among isolates not significantly different at $\leq 0.05$. 
We began the study described here in 1995 as a result of the discovery of soybean rust in Hawaii (11) and the distinct possibility that the disease might spread, perhaps on the clothes of travelers, to continental United States. In 2001, after discovery of soybean rust in Africa and South America, we expanded our study to include isolates from these areas. As a result, a second data set was generated to include studies with the new isolates. Although the data were very similar, we could not statistically justify com- bining the data obtained during the two time periods. However, because of the intentional inclusion of TW80-2 in the second set of tests, after having been used in all previous experiments, we could indirectly compare results. The results showed that all isolates were essentially identical with respect to response to temperature. Differences that did exist were very small and not statistically significant, with the exception of the b5 shape parameter for lesions per square centimeter and the observed optimum

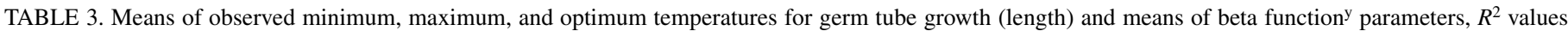

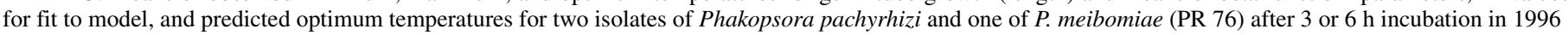

\begin{tabular}{|c|c|c|c|c|c|c|c|c|}
\hline Isolate & $T_{\min }$ & $T_{\max }$ & b1 & b3 & b5 & $\begin{array}{c}T_{\text {opt }} \\
\text { (observed) }\end{array}$ & $\begin{array}{c}T_{\mathrm{opt}} \\
\text { (predicted) }\end{array}$ & $R^{2}$ \\
\hline \multicolumn{9}{|l|}{$3 \mathrm{~h}$ incubation } \\
\hline HW94-1 & 12.60 & 29.27 & 5.02 & 0.74 & 0.41 & 22.15 & 23.40 & 0.98 \\
\hline PR76 & 11.65 & 29.78 & 0.41 & 1.18 & 1.09 & 22.15 & 22.15 & 0.91 \\
\hline TW80-2 & 12.60 & 28.27 & 1.87 & 1.12 & 0.52 & 22.15 & 23.40 & 0.99 \\
\hline Mean & 12.28 & 29.11 & 2.43 & 1.01 & 0.67 & 22.15 & 22.98 & \\
\hline Probability difference $\alpha=0.05$ & $\mathrm{NS}^{\mathrm{z}}$ & NS & NS & NS & NS & NS & NS & \\
\hline \multicolumn{9}{|l|}{$6 \mathrm{~h}$ incubation } \\
\hline HW94-1 & 9.27 & 29.40 & 9.02 & 0.86 & 0.43 & 21.05 & 22.30 & 0.98 \\
\hline PR76 & 11.50 & 29.43 & 3.83 & 0.85 & 0.71 & 20.75 & 22.25 & 0.99 \\
\hline TW80-2 & 9.27 & 30.43 & 0.77 & 1.27 & 0.85 & 21.00 & 21.00 & 0.99 \\
\hline Mean & 10.01 & 29.75 & 4.54 & 0.99 & 0.66 & 20.93 & 21.85 & \\
\hline Probability difference $\alpha=0.05$ & NS & NS & NS & NS & NS & NS & NS & \\
\hline
\end{tabular}

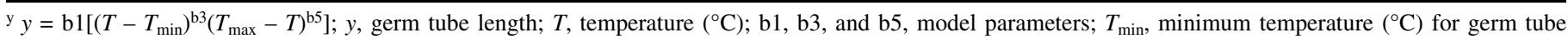
growth; $T_{\max }$, maximum temperature $\left({ }^{\circ} \mathrm{C}\right)$ for germ tube growth.

${ }^{\mathrm{z}} \mathrm{NS}=$ means among isolates not significantly different at $\leq 0.05$.

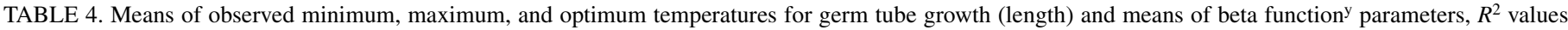
for fit to model, and predicted optimum temperatures for three isolates of Phakopsora pachyrhizi after 3 or 6 h incubation in 2005

\begin{tabular}{|c|c|c|c|c|c|c|c|c|}
\hline Isolate & $T_{\min }$ & $T_{\max }$ & b1 & b3 & b5 & $\begin{array}{c}T_{\text {opt }} \\
\text { (observed) }\end{array}$ & $\begin{array}{c}T_{\mathrm{opt}} \\
\text { (predicted) }\end{array}$ & $R^{2}$ \\
\hline \multicolumn{9}{|l|}{$3 \mathrm{~h}$ incubation } \\
\hline BZ01-1 & 10.50 & 29.63 & 0.92 & 1.38 & 0.60 & 24.37 & 23.67 & 0.99 \\
\hline TW80-2 & 9.43 & 29.07 & 0.10 & 1.49 & 0.56 & 23.67 & 24.37 & 0.99 \\
\hline ZM01-1 & 10.50 & 29.90 & 0.43 & 1.45 & 0.73 & 23.97 & 22.90 & 0.99 \\
\hline Mean & 10.14 & 29.53 & 0.48 & 1.44 & 0.63 & 24.00 & 23.65 & \\
\hline Probability difference $\alpha=005$ & $\mathrm{NS}^{\mathrm{z}}$ & NS & NS & NS & NS & NS & NS & \\
\hline \multicolumn{9}{|l|}{$6 \mathrm{~h}$ incubation } \\
\hline BZ01-1 & 8.63 & 29.47 & 4.27 & 1.09 & 0.47 & 23.37 & 22.63 & 0.97 \\
\hline TW80-2 & 9.73 & 29.47 & 2.59 & 1.15 & 0.59 & 24.17 & 22.63 & 0.99 \\
\hline ZM01-1 & 9.73 & 30.10 & 1.27 & 1.24 & 0.75 & 22.10 & 22.63 & 0.98 \\
\hline Mean & 9.36 & 29.68 & 3.04 & 1.16 & 0.60 & 23.21 & 22.63 & \\
\hline Probability difference $\alpha=005$ & NS & NS & NS & NS & NS & NS & NS & \\
\hline
\end{tabular}

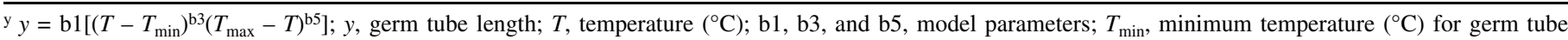
growth; $T_{\max }$, maximum temperature $\left({ }^{\circ} \mathrm{C}\right)$ for germ tube growth.

z NS $=$ means among isolates not significantly different at $\leq 0.05$.

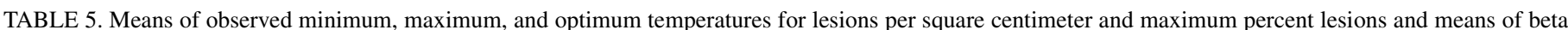
function ${ }^{\mathrm{w}}$ parameters, $R^{2}$ values for fit to model, and predicted optimum temperatures for three isolates of Phakopsora pachyrhizi

\begin{tabular}{|c|c|c|c|c|c|c|c|c|}
\hline Isolate & $\mathrm{T}_{\min }$ & $\mathrm{T}_{\max }$ & b1 & b3 & b5 & $\begin{array}{c}T_{\text {opt }} \\
\text { (observed) }\end{array}$ & $\begin{array}{c}T_{\mathrm{opt}} \\
\text { (predicted) }\end{array}$ & $R^{2}$ \\
\hline \multicolumn{9}{|l|}{ Lesions per square centimeter } \\
\hline BZ01-1 & 10.17 & 31.27 & 0.04 & 0.98 & $1.40 \mathrm{~A}^{\mathrm{x}}$ & 24.43 & 21.80 & 0.71 \\
\hline TW80-2 & 10.17 & 29.87 & 0.03 & 0.79 & $0.75 \mathrm{AB}$ & 19.33 & 21.47 & 0.87 \\
\hline ZM01-1 & 10.17 & 30.40 & 0.32 & 0.64 & $0.46 \mathrm{~B}$ & 21.47 & 21.07 & 0.82 \\
\hline Mean & 10.17 & 30.51 & 0.13 & 0.80 & 0.87 & 21.74 & 21.45 & \\
\hline Probability difference $\alpha=0.05$ & $\mathrm{NS}^{\mathrm{y}}$ & NS & NS & NS & $* \mathrm{z}$ & NS & NS & \\
\hline \multicolumn{9}{|l|}{ Maximum percent lesions } \\
\hline BZ01-1 & 10.17 & 27.97 & 0.12 & 0.68 & 0.49 & $24.43 \mathrm{~A}$ & 24.50 & 0.77 \\
\hline TW80-2 & 10.17 & 29.87 & 0.10 & 0.78 & 0.75 & $17.50 \mathrm{~B}$ & 21.47 & 0.87 \\
\hline ZM01-1 & 10.17 & 30.40 & 0.28 & 0.70 & 0.53 & $21.46 \mathrm{AB}$ & 21.07 & 0.82 \\
\hline Mean & 10.17 & 29.41 & 0.17 & 0.72 & 0.59 & 21.43 & 22.34 & \\
\hline Probability difference $\alpha=0.05$ & NS & NS & NS & NS & NS & $*$ & NS & \\
\hline
\end{tabular}

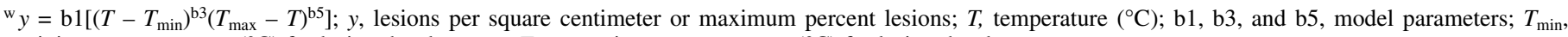
minimum temperature $\left({ }^{\circ} \mathrm{C}\right)$ for lesion development; $T_{\max }$, maximum temperature $\left({ }^{\circ} \mathrm{C}\right)$ for lesion development.

${ }^{x}$ Means not followed by the same letter are significantly different at $P \leq 0.05$.

y NS = means among isolates not significantly different at $\leq 0.05$.

${ }^{\mathrm{z}}$ Indicates a significant difference among means for isolates. 
temperature for maximum percent lesions. The range of predicted optimum temperatures for urediniospore germination and germ tube growth were virtually the same and overlapped very closely with optimum temperature ranges for lesions per square centimeter and maximum percent lesions. This indicated that temperature affected spore germination and germ tube growth in the same manner and degree as it affected initial disease development.

Our isolates behaved similarly to those described 30 years ago by Marchetti et al. (13) when they compared optimum temperature ranges for urediniospore germination and initiation of disease among isolates of $P$. pachyrhizi from Asia and Australia. However, from their data, it is not possible to determine variability among isolates in optimum temperatures for germination. Tan (21) determined that the optimum temperature range for urediniospore germination in the Peoples Republic of China was 15 to $26^{\circ} \mathrm{C}$, and Tan et al. (22) reported that the optimum temperature range for penetration from urediniospores was 22 to $26^{\circ} \mathrm{C}$, and that no penetration occurred at $28^{\circ} \mathrm{C}$ or higher. Results from Hubei Province, Republic of China, suggested that in the field at temperatures above $27^{\circ} \mathrm{C}$, rust did not occur (22). These observations are consistent with our results suggesting a high degree of similarity among isolates. We examined the effects of temperature on only a small, but important, portion of the soybean rust disease cycle. Differences among isolates may exist elsewhere, and consequently, we intend to extend our research to include the entire disease cycle. With this information, we will more fully understand the importance of temperature on rust development.

In our study, we took special care to accurately determine temperatures at the agar surface. When using the temperaturegradient plate, the major contributor to any difference between actual temperatures experienced by urediniospores and that reported in this manuscript were due to our inability to place agar dishes in a straight line across the temperature-gradient plate. In a series of experiments in which we continuously monitored temperatures, the deviation from the mean temperature at the agar surface for all dishes in a temperature compartment was never more than $\pm 0.4^{\circ} \mathrm{C}$. We believe that this variation was acceptable.

Based on numbers of lesions that developed on the highly susceptible soybean cv. Williams in this study, and on other susceptible cultivars in other studies (R. D. Frederick, M. R. Miles, and G. L. Hartman, unpublished data), we found no evidence that P. pachyrhizi varied in aggressiveness. Indeed, in the three experiments described here in which we determined lesion numbers, isolates BZ01-1, TW80-2, and ZM01-1 each produced an average of 9.1 to 11.7 lesions per square centimeter of leaf area on inoculated plants subjected to a $21^{\circ} \mathrm{C}$-dew period temperature, near optimum for disease initiation (data not shown).

Surprisingly, urediniospores of $P$. meibomiae behaved the same as those of $P$. pachyrhizi when subjected to the same temperature ranges. Although having different host preferences (17), the two rust organisms are similar in that both have extremely broad host ranges and penetrate the leaf surface directly through the cuticle following urediniospore germination, a rare mode of penetration from germinated urediniospores among rust pathogens (3).

Now that $P$. pachyrhizi has been discovered in southeastern United States, studies can be conducted outside disease containment. Results from research conducted in the laboratory, greenhouse, and field together will answer many questions that will lead to a better understanding of soybean rust and its control. Studies in the laboratory and greenhouse can provide precise information on effects of specific environmental variables, such as moisture and temperature, on portions of the disease cycle. However, the results must be verified in the field where natural field conditions exist. The results presented here indicate a great similarity in environmental requirements and pathogen aggressiveness among isolates of $P$. pachyrhizi collected from different parts of the world over a 25-year period and suggests that soybean rust prediction models will be widely applicable.

\section{ACKNOWLEDGMENTS}

The use of trade, firm, or corporation names in this publication is for the information and convenience of the reader. Such use does not constitute an official endorsement or approval by the U.S. Department of Agriculture or the Agricultural Research Service of any product or service to the exclusion of others that may be suitable. We thank $\mathrm{H}$. Tipton for excellent technical assistance in conducting the studies described in this manuscript; K. R. Bromfield, C. Levy, and J. T. Yorinori for providing pathogen isolates; and an undisclosed associate editor for the excellent suggestion to use the temperature-dependent biological response model described in this manuscript.

\section{LITERATURE CITED}

1. Analytis, S. 1977. Über die relation zwischen biologischer entwicklung und temperatur bei phytopathogenen Pilzen. Phytopathol. Z. 90:64-76.

2. Bell, F. H., Schmidt, C. G., Miller, W. E., and Kingsolver, C. H. 1952. A technique for obtaining uniform deposition of uredospores on cereal leaves. Phytopathology 42:340.

3. Bonde, M. R., Melching, J. S., and Bromfield, K. R. 1976. Histology of the suscept-pathogen relationship between Glycine max and Phakopsora pachyrhizi, cause of soybean rust. Phytopathology 66:1290-1294.

4. Bromfield, K. R. 1984. Soybean Rust. Monograph No. 11. American Phytopathological Society, St. Paul, MN.

5. Bromfield, K. R., Melching, J. S., and Kingsolver, C. H. 1980. Virulence and aggressiveness of Phakopsora pachyrhizi isolates causing soybean rust. Phytopathology 70:17-21.

6. Cherry, E., and Peet, C. E. 1966. An efficient device for the rapid collection of fungal spores from infected plants. Phytopathology 56:11021103.

7. Dalla Pria, M., Christiano, R. C. S., Furtado, E. L., Amorim, L., and Bergamin Filho, A. 2006. Effect of temperature and leaf wetness duration on infection of sweet oranges by Asiatic citrus canker. Plant Pathol. 55:657-663.

8. Halldal, P., and French, C. S. 1958. Algal growth in crossed gradients of light intensity and temperature. Plant Physiol. 33:249-252.

9. Hennings, P. 1903. Some new Japanese Uredinales. IV. Hedwigia (Suppl.):107-108. (In German.)

10. Kingsolver, C. H., Melching, J. S., and Bromfield, K. R. 1983. The threat of exotic plant pathogens to agriculture in the United States. Plant Dis. 67:595-600.

11. Killgore, E., and Heu, R. 1994. First report of soybean rust in Hawaii. Plant Dis. 78:1216.

12. Levy, C. 2005. Epidemiology and chemical control of soybean rust in southern Africa. Plant Dis. 89:669-674.

13. Marchetti, M. A., Melching, J. S., and Bromfield, K. R. 1976. The effects of temperature and dew period on germination and infection by urediospores of Phakopsora pachyrhizi. Phytopathology 66:461-463.

14. Melching, J. S., Bromfield, K. R., and Kingsolver, C. H. 1979. Infection, colonization, and uredospore production on Wayne soybean by four cultures of Phakopsora pachyrhizi, the cause of soybean rust. Phytopathology 69:1262-1265.

15. Melching, J. S., Bromfield, K. R., and Kingsolver, C. H. 1983. The plant pathogen containment facility at Frederick, Maryland. Plant Dis. 77: 717-722.

16. Melching, J. S., Dowler, W. M., Koogle, D. L., and Royer, M. H. 1989. Effects of duration, frequency, and temperatures of leaf wetness periods on soybean rust. Plant Dis. 73:117-122.

17. Miles, M. R., Frederick, R. D., and Hartman, G. L. 2003. Soybean rust: Is the U. S. soybean crop at risk? APSnet feature. Online publication. American Phytopathological Society, St. Paul, MN.

18. Morel, W., and Yorinori, J. T. 2002. Situacion de la roja de la soja en el Paraguay. Bol de Diulgacion No. 44. Ministerio de Agricultura y Granaderia, Centro Regional de investigacion Agricola, Capitan Miranda, Paraguay.

19. Ono, Y., Buritica, P., and Hennen, J. F. 1992. Delimitation of Phakopsora, Physopella and Cerotelium and their species on Leguminosae. Mycol. Res. 96:825-850.

20. Schneider, R. W., Hollier, C. A., Whitan, H. K., Palm, M. E., McKemy, J. M., Hernandez, J. R., Levy, L., and DeVries-Paterson, R. 2005. First report of soybean rust caused by Phakopsora pachyrhizi in the continental United States. Plant Dis. 89:774.

21. Tan, Y. 1994. Epidemiology of soybean rust in China. Pages 50-58 in: The Advance of Soybean Rust Research. Proceedings of a meeting held in 
1992. Hubei Science and Technology Publishing House, Wuhan, Peoples Republic of China.

22. Tan, Y., Yu, Z., and Liu, J. 1994. Epidemic control of soybean rust caused by Phakopsora pachyrhizi Syd. Pages 36-48 in: The Advance of Soybean Rust Research. Proceedings of a meeting held in 1992. Hubei Science and Technology Publishing House, Wuhan, Peoples Republic of China.
23. Vakili, N. G., and Bromfield, K. R. 1976. Phakopsora rust on soybean and other legumes in Puerto Rico. Plant Dis. Rep. 60:995-999.

24. Yorinori, J. T., Paiva, W. M., Frederick, R. D., Costamilan, L. M., Bertagnolli, P. F., Hartman, G. L., Goday, C. V., and Nunes, J. J. 2003. Epidemics of soybean rust (Phakopsora pachyrhizi) in Brazil and Paraguay from 2001 to 2003. Plant Dis. 89:675-677. 